\title{
Turner Syndrome, Uncommonly Diagnosed Cause of Short Stature: Case Report and Review of Literature
}

\author{
Basnet $\mathrm{S}^{1}$, Eleena $\mathrm{A}^{2}$, Sharma $\mathrm{AK}^{3}$ \\ ${ }^{1}$ Dr. Srijana Basnet, MBBS, MD. Assistant Professor, \\ ${ }^{2} \mathrm{Dr}$. Aistha Eleena, MBBS, MD Resident, ${ }^{3} \mathrm{Dr}$. Arun \\ Kumar Sharma, MBBS, MD. Assistant Professor. All \\ from the Department of Paediatrics, Institute of Medicine, \\ Tribhuvan University Teaching Hospital, Maharajgunj, \\ Kathmandu, Nepal.
}

\section{Introduction}

T urner's syndrome, a condition characterized by the complete or partial absence of second sex chromosome, is defined by a combination of phenotypic features ${ }^{1}$. It is characterized by edema of dorsum of dorsum of hand and feet, low birth weight, webbing of neck, low hair line, small mandible prominent auricula, epicanthic fold, wide sized thorax, widely spaced nipple, high arched palate, short stature, cubitus valgus, gonadal dysgenesis, primary amenorrhoea. Pelvic kidney, horse shoe kidney, ureteric duplication, ureteropelvic narrowing, hydronephrosis are urinary abnormalities most commonly associated with Turner syndrome. It is estimated that approximately 1 in 2000 to 1 in 5000 female live-born phenotypic females are affected $^{2}$.

\section{The Case}

A 40 months old girl was admitted in paediatric ward for evaluation of short stature. The child was not gaining proper height as per her age since early infancy. She was term baby delivered at home with birth weight of $2.2 \mathrm{kgs}$. She had recurrent episodes of pneumonia requiring hospital admissions and her echocardiography done in the past showed only mild left ventricular hypertrophy and mild tricuspid regurgitation. She started to sit without support at 13 months and started to walk without support at 20 months. Other developmental domains were normal.

\begin{abstract}
Many children are frequently brought to the paediatric clinic for evaluation of short stature. Evaluation for these children does not go beyond $\mathrm{x}$-ray for bone age estimation and growth hormone analysis. Most of them are considered having constitutional or genetic cause for their short stature. However, shuttle dysmorphic features could be missed in many of them. Hence, many children might be having chromosomal anomaly as an underlying cause.
\end{abstract}

We report a case of 40 months who had been evaluated several times in the past for pneumonia, otitis media and short stature is finally diagnosed to have Turner syndrome.

Findings on her physical examination included:

Short stature with a height of $77.5 \mathrm{~cm}(79.8 \%$ of median of NDHS growth chart).(Figure-1), Her mid parental height was $153 \mathrm{~cm}$ which lie on $5^{\text {th }}$ percentile. Frontal bossing, flat nasal bridge, single palmer crease in both hands and low set ears, high arched palate, webbed neck. (Figure 2) and broad chest with widely spaced nipples. Her blood pressure in right upperlimb was $142 / 78 \mathrm{mmHg}$, left upper limb was $150 / 87 \mathrm{mmHg}$, right lower limb 123/69 mmHg, left lower limb 115/94 $\mathrm{mmHg}$ with pulse of $86 / \mathrm{min}$. Her radial pulse was good volume but femoral and lower limb pulses were not palpable. On CVS examination, S1 and S2 were normal with grade 3 systolic murmur most prominently heard over left infraclavicular area.

Due to her clinical features, Turner syndrome was suspected and confirmed by band karyotyping. Her blood pressure was controlled with amlodipine and atenolol. Chest X-ray revealed cardiomegaly. Her echocardiography revealed dilated coronary sinus with coarctation of aorta. Her ENT evaluation revealed

\footnotetext{
Address for correspondence

Dr. Srijana Basnet

Assistant Professor

Department of Paediatrics,

Institute of Medicine, Tribhuvan University Teaching Hospital,

Maharajgunj, Kathmandu, Nepal.

E-mail:drsrijanabasnet@yahoomail.com
}

\author{
How to cite this article ? \\ Basnet S, Eleena A, Sharma AK. Turner Syndrome, Uncommonly \\ Diagnosed Cause of Short Stature: Case Report and Review of \\ Literature. J Nepal Paediatr Soc 2013;33(1):74-76.
}




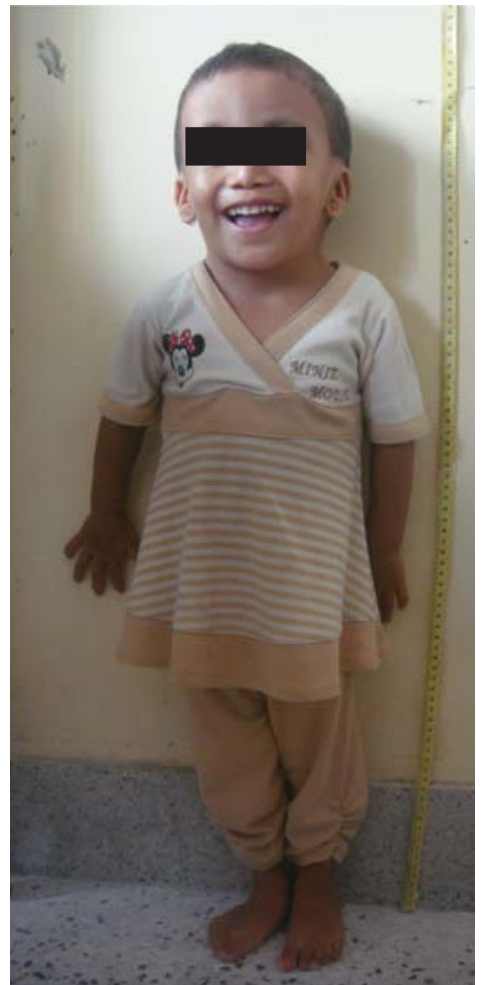

Fig 1: Short statured girl with facial dysmorphism (photo taken permission from parents)

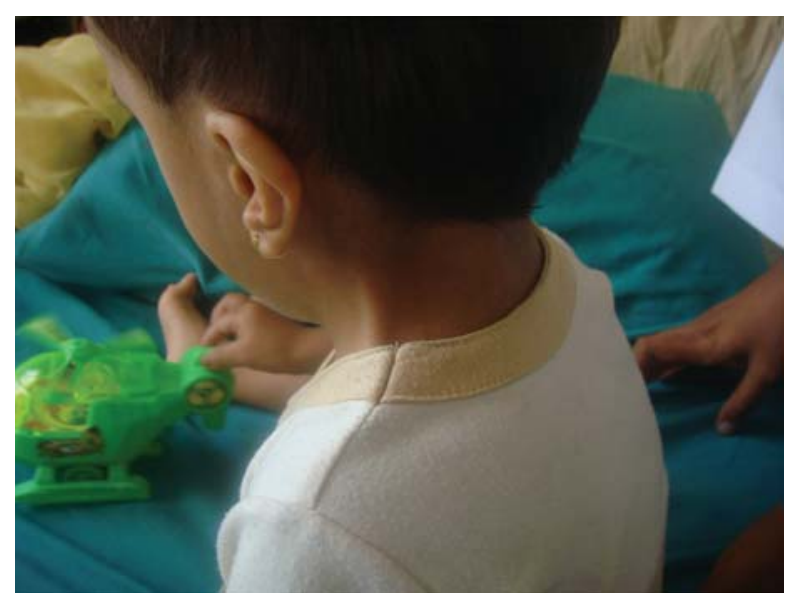

Fig 2: Showing webbing of the neck

bilateral otitis media with effusion with normal hearing assessment. Her thyroid function and ultrasound of abdomen were normal. She underwent repair of coarctation of aorta. Postoperatively her blood pressure was under control without antihypertensive drugs.

\section{Discussion}

Common causes for short stature in children include constitutional, genetic short stature. However, underlying systemic problem or chromosomal anomaly could be unusual underlying causes. Due to characteristic features like webbing of neck, low hair line, widely spaced nipple, high arched palate and cardiac examination suggestive of coarctation of aorta along with short stature, Turner syndrome was suspected in our patient. These features were missed during her previous hospital visits. One study showed that the diagnosis of Turner syndrome is made on an average of seven years after short stature is clinically evident on female growth curves $^{3}$. In a case series, 4 percent of girls referred for genetic evaluation of isolated short stature, regardless of familial background height, were diagnosed with Turner's syndrome ${ }^{4}$.

$20 \%$ of girls with Turner syndrome have cardiac anomaly and $50 \%$ of them have coarctation of aorta $^{5,6}$. Up to $40 \%$ of girls with Turner syndrome have hypertension $^{7}$ and when identified, it should be treated vigorously. Hypertension in our patient was due to coarctation of aorta, however renal abnormalities could be another cause for hypertension in these children so USG abdomen should be done to exclude anatomical abnormalities of kidney.

Sensorineural hearing deficits are common and the frequency increases with age so ENT evaluation was done for our patient and otitis media with effusion was detected. Recurrent bilateral otitis media develops in about $75 \%$ of patients because of abnormalities in the middle ear and eustachian tube. High arched palate also leads to infection by impairing the fluid drainage in the middle ear. In addition, a progressive midfrequency sensorineural hearing loss often occurs, which necessitates the use of hearing aids in some children ${ }^{8}$.

Problems with gross and fine motor-sensory integration, failure to walk before 15 months of age and early language dysfunction often raise questions about developmental delay but intelligence is normal in most cases ${ }^{9}$. Our patient also had delay in gross motor milestones.

Although $45, X$ is the karyotype typically seen in patients with Turner's syndrome, other sex chromosome anomalies such as isochromosome $\mathrm{Xq}$, ring $\mathrm{X}$, deletion $\mathrm{Xp}$, or an abnormal $\mathrm{Y}$ chromosome can also cause this condition ${ }^{10}$. The single $X$ is of maternal origin in $50-70 \%$ of patients.

\section{Conclusion}

Features of Turner syndrome should be looked for in a female child with short stature, and if she has features suggestive of Turner syndrome, she should be evaluated for systemic problems also.

\section{References}

1. M. Descartes, A.J Caroll. Cytogenetics. In: Kliegman, Behrman, Jenson editors. Nelson Text book of Pediatrics. 18 ${ }^{\text {th }}$ edition. India: Elsevier; 2008. p.2386-89. 
2. Jones KL. XO syndrome. In Smith's Recognizable Patterns of Human Malformation. 5th ed. Philadelphia, Pa.: Elsevier Saunders, 2006. p.81.

3. Savendahl L, Davenport ML. Delayed diagnoses of Turner syndrome: proposed guidelines for change. J Pediatr 2000;137(4):455-9.

4. Moreno-Garcia M, Fernandez-Martinez FJ, Barreiro Miranda E. Chromosomal anomalies in patients with short stature. Pediatr Int 2005;47(5):546-9.

5. Clark EB. Neck web and congenital heart defects: a pathogenic association in $45 \mathrm{X}$-O Turner syndrome. Teratology 1984;29:355-61.

6. Lacro RV, Jones KL, Benirschke K. Coarctation of the aorta in Turner syndrome: a pathologic study of fetuses with nuchal cystic hygromas, hydrops fetalis, and female genitalia. Pediatrics 1988;81:445-51.

7. Sybert VP. Cardiovascular malformations and complications in Turner syndrome. Pediatrics 1998;101(1).

8. Stenberg AE, Nylen $O$, Windh $M$, Hultcrantz $M$. Otological problems in children with Turner's syndrome. Hear Res 1998;124(1-2):85-90.

9. Zinn AR, Page DC, Fisher EMC. Turner Syndrome: The Case of the missing $\mathrm{X}$ chromosome. Trends Genet 1993;9(3):90-93.

10. Sanders RC, Blackmon LR. Structural Fetal Abnormalities: The Total Picture. 2nd ed. St. Louis,Mo.: Mosby, 2002:15-16. 